\title{
Managing, exploiting and sharing cadastral databases in district 6, Ho Chi Minh City: Present status and solutions
}

\author{
Linh D. T. Truong*, \& Thy N. Nguyen
}

Faculty of Land and Real Estate Management, Nong Lam University, Ho Chi Minh City, Vietnam

\begin{tabular}{|c|c|}
\hline ARTICLE INFO & ABSTRACT \\
\hline $\begin{array}{l}\text { Keywords } \\
\text { Cadastral database } \\
\text { Exploiting } \\
\text { Information system } \\
\text { Managing } \\
\text { Sharing }\end{array}$ & $\begin{array}{l}\text { As one of the first unit in Vietnam which got cadastral } \\
\text { database, so the database of district } 6 \text {, Ho Chi Minh City is } \\
\text { quite limited in terms of building process, content and data } \\
\text { structure. The database does not comply with the current reg- } \\
\text { ulations of Ministry of Natural Resources and Environment, } \\
\text { and not synchronized with cadastral database of other locali- } \\
\text { ties. The Ho Chi Minh City Department of Natural Resources } \\
\text { and Environment (2014) concluded that these limitations led } \\
\text { to difficulties in managing, exploiting and sharing their cadas- } \\
\text { tral database. The research aimed to the needs of society } \\
\text { in reality and local characteristics in managing, exploiting } \\
\text { and sharing cadastral database. As the study identified the } \\
\text { advanatages and disadvantages of the current database and } \\
\text { proposed appropriate solutions to complete this work for Dis- } \\
\text { trict } 6 \text { in particular and Ho Chi Minh City in general. The } \\
\text { new database improved the efficiency of cadastral database } \\
\text { in land management and other related fields. The results of } \\
\text { this study can be applied to completee and manage cadastral } \\
\text { database in the citywide centralized model that is potential } \\
\text { in contributing to the e-government and modern land admin- } \\
\text { istration system in Ho Chi Minh City. }\end{array}$ \\
\hline
\end{tabular}

Cited as: Truong, L. D. T., \& Nguyen, T. N. (2019). Managing, exploiting and sharing cadastral databases in district 6, Ho Chi Minh City: Present status and solutions. The Journal of Agriculture and Development 18(2), 27-38. 


\title{
Quản lý, khai thác và chia sẻ cơ sở dữ liệu địa chính tại Quận 6, Thành phố Hồ Chí Minh: Thực trạng và giải pháp
}

\author{
Trương Đỗ Thùy Linh* \& Nguyễn Ngọc Thy
}

Khoa Quản Lý Đất Đai và Bất Động Sản, Trường Đại Học Nông Lâm TP. Hồ Chí Minh, TP. Hồ Chí Minh

\section{THÔNG TIN BÀI BÁO}

Bài báo khoa học

Ngày nhận: 14/08/2018

Ngày chỉnh sửa: 18/10/2018

Ngày chấp nhận: 05/11/2018

\section{Từ khóa}

Chia sẻ

Cơ sở dữ liệu địa chính

Hệ thống thông tin

Khai thác

Quản lý

*Tác giả liên hệ

Trương Đỗ Thùy Linh

Email: truongdothuylinh@hcmuaf.edu.vn

\section{TÓM TẮT}

Với vai trò là một trong những đơn vị đầu tiên xây dựng thành công cơ sở dữ liệu địa chính nên cơ sở dữ liệu của Quận 6, TP.HCM tồn tại khá nhiều hạn chế; đặc biệt là quy trình xây dựng, nội dung và cấu trúc dư liệu chưa phù hợp theo quy định của Bộ Tài nguyên và Môi trường cũng như không đồng bộ với cơ sở dữ liệu địa chính của các địa phương khác. Sở Tài nguyên và Môi trường TP.HCM đã khẳng định: đây là nguyên nhân gây ra nhiều khó khăn trong công tác quản lý, khai thác và chia sẻ cơ sở dữ liệu địa chính trên địa bàn. Nghiên cứu được tiếp cận theo hướng đi từ nhu cầu thực tế xã hội và đặc thù của địa phương trong công tác quản lý, khai thác và chia sẻ cơ sở dữ liệu địa chính. Từ đó, rút ra ưu - khuyết điểm và những vấn đề còn tồn tại, làm cơ sở để đề xuất các giải pháp phù hợp nhằm hoàn thiện công tác này cho Quận 6 nói riêng và TP.HCM nói chung. Kết quả đạt được giúp nâng cao hiệu quả của cơ sở dữ liệu địa chính trong quản lý đất đai và các lĩnh vực có liên quan, tiến đến hoàn thiện cơ sở dữ liệu địa chính theo mô hình tập trung toàn thành phố, cũng như đáp ứng yêu cầu của quá trình phát triển chính quyền điện tử và hệ thống quản lý đất đai hiện đại tại TP.HCM.

\section{1. Đặt Vấn Đề}

Theo Truong (2012), Quận 6, TP.HCM là một trong những đơn vị tiên phong trong cả nước xây dựng thành công cơ sở dữ liệu địa chính bằng việc tích hợp đầy đủ các thông tin không gian và thuộc tính liên quan đến toàn bộ thửa đất và quá trình quản lý, sử dụng đất trên địa bàn. Đồng thời, quận 6 số hóa được toàn bộ hồ sơ thủ tục đăng ký đất đai và gắn kết trực tiếp với cơ sở dữ liệu địa chính. Kết quả này đã hỗ trợ rất đắc lực cho hầu hết các lĩnh vực của công tác quản lý đất đai trên địa bàn.

Tuy nhiên, vì là một trong những đơn vị đầu tiên được vận hành cơ sở dữ liệu địa chính nên cơ sở dữ liệu của Quận 6 chưa thật sự hoàn chỉnh, đặc biệt là quy trình xây dựng, nội dung và cấu trúc dữ liệu chưa phù hợp theo quy định của ngành cũng như không đồng bộ với cơ sở dữ liệu địa chính của các địa phương khác. Vấn đề này đã gây nhiều bất cập và khó khăn trong công tác quản lý, khai thác và chia sẻ cơ sở dữ liệu địa chính tại địa phương, đặc biệt là công tác đồng bộ và tích hợp cơ sở dữ liệu giữa các cấp (DONRE, 2014).

Nghiên cứu này đánh giá thực trạng quản lý, khai thác và chia sẻ cơ sở dữ liệu địa chính của Quận 6, TP.HCM. Từ đó, một số giải pháp nhằm hoàn thiện công tác này tại địa phương sẽ được đề xuất để tiến đến hoàn thiện và quản lý cơ sở dữ liệu địa chính theo mô hình tập trung trên toàn thành phố, đáp ứng các yêu cầu của hệ thống chính quyền điện tử và làm tiền đề cho quá trình phát triển hệ thống quản lý đất đai hiện đại tại 


\section{TP.HCM.}

\section{Vật Liệu và Phương Pháp Nghiên Cứu}

\section{1. Đối tượng nghiên cứu}

Đối tượng nghiên cứu là số liệu, dữ liệu địa chính đang vận hành tại chi nhánh Văn phòng Đăng ký đất đai Quận 6 và thực trạng quản lý, khai thác, chia sẻ cơ sở dữ liệu địa chính tại địa phương.

\subsection{Phương pháp nghiên cứu}

\subsubsection{Phương pháp thu thập tài liệu, dữ liệu}

Nghiên cứu tiến hành thu thập các tài liệu, dữ liệu cần thiết gồm: tài liệu lý luận; các công trình nghiên cứu đã được công bố; tài liệu, cơ sở dữ liệu địa chính; các quy trình giải quyết hồ sơ đất đai và quy chế, quy định liên quan đến vấn đề quản lý, khai thác và chia sẻ cơ sở dữ liệu địa chính tại Tổng cục Quản lý đất đai, Phòng Tài nguyên và Môi trường, Chi nhánh Văn phòng Đăng ký đất đai Quận 6 và tại các phòng, ban, đơn vị trực thuộc Sở Tài nguyên và Môi trường TP.HCM.

\subsubsection{Phương pháp thống kê}

Dựa vào kết quả trích xuất cơ sở dữ liệu địa chính cũng như các tài liệu thu thập được, tiến hành thống kê những thông tin về không gian, thuộc tính địa chính và những số liệu có liên quan đến quá trình vận hành cơ sở dữ liệu địa chính của Quận 6. Trên cơ sở đó, thực hiện đánh giá thực trạng và hiệu quả của công tác quản lý, khai thác và chia sẻ cơ sở dữ liệu địa chính tại địa phương.

\subsubsection{Phương pháp phỏng vấn}

Nghiên cứu tiến hành phỏng vấn một số lãnh đạo và cán bộ chuyên môn thuộc Tổng cục Quản lý đất đai; Sở Tài nguyên và Môi trường TP.HCM; Sở Thông tin và truyền thông TP.HCM; Chi nhánh Văn phòng Đăng ký đất đai Quận 6; Cục thuế TP.HCM và các Văn phòng Đăng ký đất đai TP.HCM, Bình Dương, An Giang, Vĩnh Long. Nội dung phỏng vấn xoay quanh các vấn đề chính như sau: (1) thực trạng quản lý, khai thác và chia sẻ cơ sở dữ liệu địa chính tại Quận 6; (2) thuận lợi, khó khăn và bất cập trong quá trình vận hành và khai thác cơ sở dữ liệu; (3) hiệu quả của cơ sở dữ liệu địa chính đối với công tác quản lý đất đai và các lĩnh vực có liên quan; (4) các tiêu chí cần thiết về phần mềm, cơ sở vật chất và hạ tầng công nghệ thông tin hỗ trợ vận hành cơ sở dữ liệu địa chính; (5) thực trạng và cách thức vận hành các mô hình quản lý, khai thác, chia sẻ cơ sở dữ liệu địa chính đạt hiệu quả cao tại một số địa phương; (6) quy định, quy trình bổ sung, cập nhật và hoàn thiện cơ sở dữ liệu địa chính; và (7) quy định về kiến trúc và mô hình hệ thống thông tin đất đai cấp tỉnh.

\subsubsection{Phương pháp phân tích, tổng hợp}

Sau khi phỏng vấn chuyên gia và thu thập đầy đủ dữ liệu, tài liệu, số liệu, nghiên cứu tiến hành phân tích các kết quả đạt được cũng như các tài liệu có liên quan nhằm khai thác những vấn đề cần thiết trong quản lý và vận hành cơ sở dữ liệu địa chính. Từ đó, nghiên cứu xác định được các ưu - khuyết điểm của công tác quản lý, khai thác và chia sẻ cơ sở dữ liệu địa chính tại Quận 6 và cuối cùng đưa ra một số giải pháp phù hợp nhằm hoàn thiện công tác này tại địa phương.

\section{Kết Quả và Thảo Luận}

\section{1. Đặc điểm cơ sở dữ liệu địa chính Quận 6}

Theo DONRE (2014), cơ sở dữ liệu địa chính Quận 6 được xây dựng theo Quyết định số 5946/QĐ-UBND ngày 29/12/2009 của Ủy ban nhân dân TP.HCM và được chính thức nghiệm thu, đưa vào khai thác ngày $30 / 12 / 2011$, với các đặc điểm sau:

Cơ sở dữ liệu được thiết kế với cấu trúc dữ liệu tuân thủ theo chuẩn dữ liệu địa chính quy định tại thông tư số 17/2010/TT-BTNMT của Bộ Tài nguyên và Môi trường.

Cơ sở dữ liệu lưu trữ đầy đủ các dữ liệu không gian địa chính, dữ liệu thuộc tính địa chính và dữ liệu hồ sơ thủ tục đăng ký đất đai dạng số.

Vận hành thống nhất bởi phần mềm HCM's Land MDP, trên nền ứng dụng Desktop, theo mô hình cơ sở dữ liệu phân tán (trong đó, chỉ dữ liệu về đất hộ gia đình, cá nhân được lưu trữ tại Quận, còn dữ liệu về đất tổ chức lại được lưu trữ tại Thành phố).

Cơ sở dữ liệu thuộc tính được quản lý bằng hệ quản trị cơ sở dữ liệu Microsoft SQL Server. Cơ sở dữ liệu không gian được quản lý bằng bộ công cụ ArcGIS.

Tất cả các hồ sơ thủ tục hành chính liên quan đến quá trình đăng ký đất đai của quận đều được 
thực hiện trên cơ sở dữ liệu địa chính và hoàn thành trước khi trao giấy chứng nhận cho người dân.

Quá trình cập nhật cơ sở dữ liệu địa chính của Quận được thực hiện trên môi trường tác nghiệp điện tử, tuân thủ đúng bộ thủ tục hồ sơ hành chính về đất đai của Ủy ban nhân dân TP.HCM.

3.2. Đánh giá thực trạng quản lý, khai thác và chia sẻ cơ sở dữ liệu địa chính tại Quận 6

\subsection{1. Đánh giá thực trạng quản lý cơ sở dữ liệu địa chính}

- Hạ tầng kỹ thuật công nghệ thông tin của địa phương:

Về hệ thống trang thiết bị: Quận 6 được trang bị đầy đủ các thiết bị phục vụ khai thác, cập nhật dữ liệu thường xuyên. Tuy nhiên, chỉ có 2 máy chủ với cấu hình trung bình, được trang bị từ năm 2011, chưa đáp ứng yêu cầu và gây nhiều rủi ro với cơ sở dữ liệu khi xảy ra sự cố. Danh mục thiết bị phục vụ vận hành cơ sở dữ địa chính của Quận 6 được trình bày ở Bảng 1 .

Bảng 1. Danh mục thiết bị phục vụ vận hành cơ sở dữ địa chính của Quận 6

\begin{tabular}{clc}
\hline STT Danh mục thiết bị & $\begin{array}{c}\text { Số } \\
\text { lượng } \\
\text { (cái) }\end{array}$ \\
\hline 1 & Máy chủ cơ sở dữ liệu & 2 \\
2 & Màn hình điện tử & 1 \\
3 & Máy tính để bàn & 44 \\
4 & Máy tính xách tay & 2 \\
5 & Máy in A4 & 7 \\
6 & Máy in A3 & 2 \\
7 & Máy photocopy & 2 \\
8 & Máy quét A4 & 1 \\
9 & Máy quét A3 & 1 \\
10 & Bộ chuyển mạch (Switch) & 3 \\
11 & Máy đọc mã vạch & 2 \\
12 & Thiết bị lưu trữ HDD 3,5”, 2TB & 1 \\
\hline
\end{tabular}

Về đường truyền kết nối: hệ thống mạng cục bộ (LAN) khá hoàn chỉnh đảm bảo vận hành thông suốt cơ sở dữ liệu địa chính trong nội bộ địa phương. Ngoài ra, Quận 6 cũng được kết nối với hệ thống mạng MetroNET TP.HCM (trên nền cáp quang, tốc độ $2 \mathrm{Mbps}$ ) để kết nối trực tuyến với Sở Tài nguyên và Môi trường và Văn phòng Đăng ký đất đai. Tuy nhiên, hệ thống đường truyền này không thông suốt, chưa đáp ứng được nhu cầu truy xuất dữ liệu với mức độ cao và liên tục.

- Mô hình quản lý, vận hành cơ sở dữ liệu địa chính:

Cơ sở dữ liệu địa chính của Quận 6 được quản lý và vận hành độc lập theo mô hình phân tán (Truong, 2012). Mô hình vận hành cơ sở dữ liệu địa chính phân tán thể hiện ở Hình 1 (DONRE, 2016). Theo đó, cơ sở dữ liệu địa chính của Quận đặt tại chi nhánh Văn phòng đăng ký đất đai (chứa dữ liệu về đất hộ gia đình, cá nhân) được sao lưu định kỳ và gửi về Sở Tài Nguyên và Môi Trường để đồng bộ vào cơ sở dữ liệu địa chính của Thành phố (chứa dữ liệu về đất tổ chức).

Với đặc thù là địa phương có mức độ truy cập dữ liệu cao và liên tục nhưng hạ tầng công nghệ thông tin hiện tại chưa đáp ứng yêu cầu thì mô hình cơ sở dữ liệu phân tán tạm thời phù hợp với Quận 6. Tuy nhiên, thực tế cho thây hiện trạng mô hình cơ sở dữ liệu này tồn tại nhiều bất cập. Cụ thề:

Không thể quản lý tập trung cơ sở dữ liệu địa chính tại một đầu mối.

Thông tin đất đai bị phân tán, thiếu tập trung và không được đồng bộ kịp thời với cấp trên, làm giảm giá trị thông tin và gây nhiều khó khăn trong cập nhật, truy xuất và chia sẻ thông tin đất đai.

Phải thực hiện sao lưu và giao nộp bản sao cơ sở dữ liệu định kỳ, ảnh hưởng đến độ an toàn và bảo mật cơ sở dữ liệu.

Tốn chi phí đầu tư trang thiết bị riêng cho địa phương (gồm: hệ thống máy chủ, thiết bị hỗ trợ).

Người quản trị hệ thống của địa phương không được đào tạo chuyên ngành về công nghệ thông tin nên không thể đáp ứng tốt yêu cầu của công tác quản trị hệ thống.

- Quản lý và đảm bảo an toàn cơ sở dữ liệu địa chính:

Theo quy định của DONRE (2016), Quận 6 tuân thủ khá tốt các quy định về quản lý cơ sở dữ liệu địa chính như:

Cơ sở dữ liệu địa chính chỉ tồn tại duy nhất một phiên bản.

Hệ thống máy chủ và phần mềm HCM's Land MDP luôn vận hành liên tục.

Các biến động đất đai được cập nhật trực tiếp vào cơ sở dữ liệu địa chính thông qua phần mềm HCM's Land MDP. 


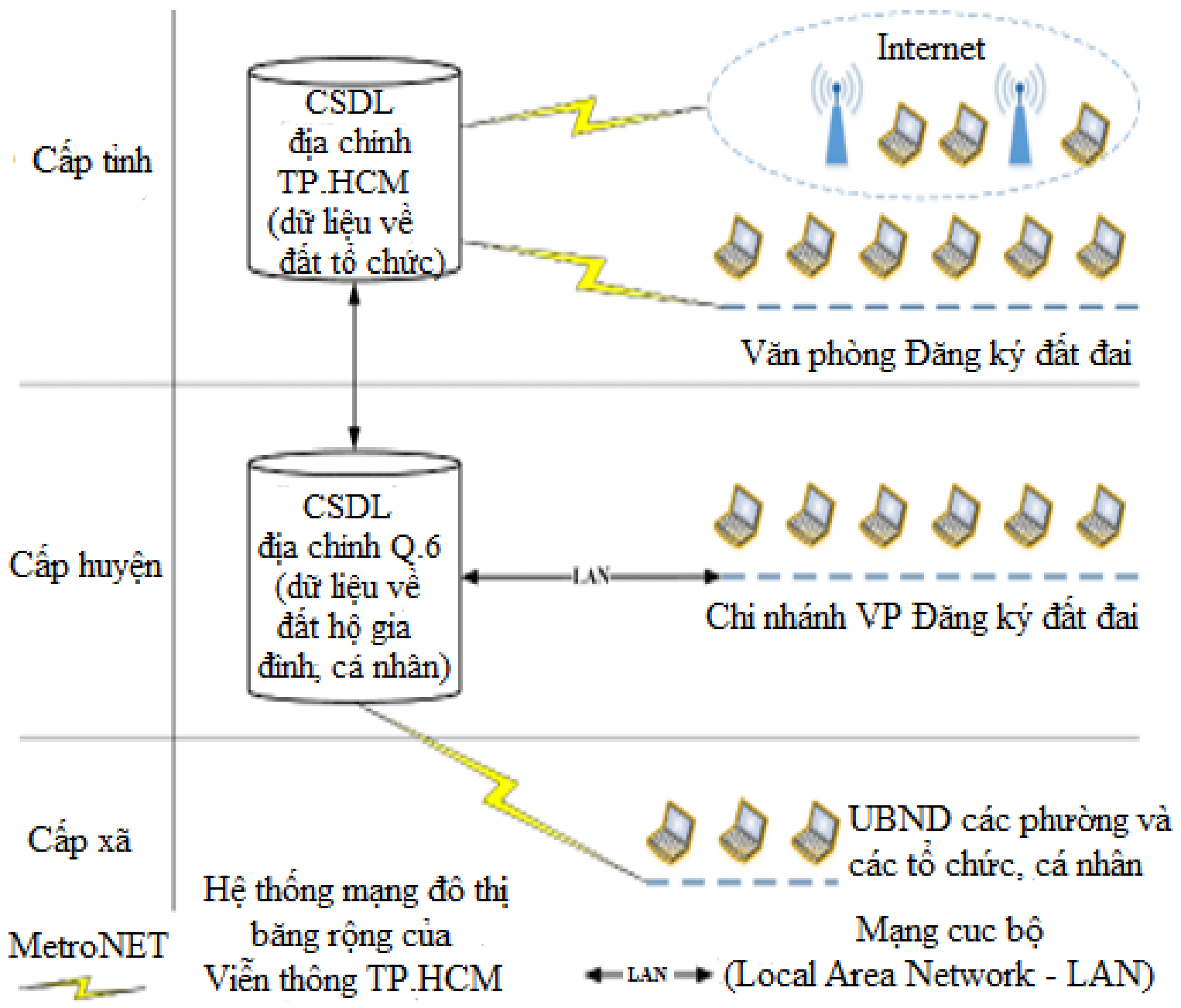

Hình 1. Mô hình vận hành cơ sở dữ liệu địa chính phân tán.

Mọi cập nhật trên cơ sở dữ liệu địa chính đều được tự động ghi nhận vào nhật ký phần mềm.

Cơ sở dữ liệu được sao lưu tự động 2 lần/ngày và được lưu vào thiết bị nhớ ngoại vi.

Đồng bộ, tích hợp cơ sở dữ liệu về Văn phòng đăng ký đất đai để nhập vào cơ sở dữ liệu địa chính của thành phố theo định kỳ 15 ngày.

- Phân quyền và quản trị người dùng tác nghiệp trên cơ sở dữ liệu địa chính:

Ứng với từng nhiệm vụ được phân công, 44 cán bộ của địa phương đều được cấp tài khoản và phân quyền (theo 3 cấp độ: quản trị, lãnh đạo và người dùng thông thường) khi tham gia vào quá trình khai thác và cập nhật cơ sở dữ liệu địa chính, đảm bảo tính an toàn, an ninh, bảo mật thông tin người dùng và cơ sở dữ liệu (BOLRD6, 2017).
Nhìn chung, cơ sở dữ liệu địa chính của Quận 6 được quản lý đúng quy định, giúp đảm bảo các yêu cầu về tính pháp lý, tính duy nhất, tính toàn vẹn, tính sẵn sàng sử dụng và tính lịch sử của cơ sở dữ liệu.

\subsection{2. Đánh giá thực trạng khai thác cơ sở dữ liệu địa chính}

Tính đến nay, qua truy xuất thông tin từ cơ sở dữ liệu địa chính đang vận hành tại chi nhánh Văn phòng Đăng ký đất đai Quận 6 thì hiện cơ sở dữ liệu địa chính địa phương chứa: 55.507 bản ghi về người (bao gồm: người quản lý, sử dụng đât và chủ sở hữu tài sản gắn liền với đất), 53.742 bản ghi về thửa đất, 44.123 bản ghi về tài sản gắn liền với đất và 56.176 bản ghi về giấy chứng nhận các loại. 
- Đối với công tác kê khai đăng ký đất đai, cấp giấy chứng nhận:

Với cơ sở dữ liệu địa chính và hệ thống quản lý quy trình xử lý hồ sơ tự động, công tác giải quyết hồ sơ cấp giấy chứng nhận của địa phương đã có nhiều cải thiện. Tát cả hồ sơ đều được thao tác và cập nhật trực tiếp vào cơ sở dữ liệu bằng phần mềm HCM's Land MDP. Đồng thời, giấy chứng nhận và các giấy tờ, văn bản kèm theo hồ sơ cũng được in tự động từ phần mềm này.

Kết quả giải quyết hồ sơ cấp giấy chứng nhận tại địa phương từ khi có cơ sở dữ liệu đến nay là 3.731 hồ sơ/năm, tăng đột biến so với giai đoạn trước (chỉ giải quyết được trung bình 874 hồ sơ/năm), đã cho thấy rõ hiệu quả của cơ sở dữ liệu địa chính đối với công tác này tại Quận 6 .

Tuy nhiên, việc thể hiện thông tin về sơ đồ hình thể nhà đất lên giấy chứng nhận vẫn được thể hiện thủ công bằng cách photocopy từ bản vẽ người dân cung cấp, khiến địa phương không thể quản lý được trọn vẹn thông tin pháp lý của thửa đất trên cơ sở dữ liệu địa chính.

- Đối với công tác cập nhật, chỉnh lý và quản lý biến động đất đai:

Tương tự như trên, việc vận hành cơ sở dữ liệu địa chính đối với công tác này tại Quận 6 đã mang lại hiệu quả rất lớn về nhiều mặt. Kết quả thống kê cho thấy, số lượng hồ sơ cập nhật, chỉnh lý biến động đất đai trung bình từ khi địa phương vận hành cơ sở dữ liệu đến nay là 9.410 hồ sơ/năm, tăng gấp 9 lần so với trước đó (chỉ giải quyết được 1.149 hồ sơ/năm).

Tuy nhiên, hiện nay quận 6 chỉ thực hiện cập nhật, chỉnh lý biến động thuộc tính địa chính vào cơ sở dữ liệu, tất cả các biến động về không gian được địa phương cập nhật, chỉnh lý và quản lý trên hệ thống bản đồ địa chính (ở định dạng *.dgn), khiến thông tin không gian địa chính không thống nhất với hồ sơ gốc và hiện trạng sử dụng đất ngoài thực địa.

- Đối với công tác lập và quản lý hồ sơ địa chính:

Quận 6 lập và quản lý sổ bộ địa chính hoàn toàn tự động trên máy tính, với 36 sổ mục kê, 242 sổ địa chính và 27 sổ theo dõi biến động đất đai. Theo BOLRD6 (2017), hiện địa phương không lập và sử dụng sổ bộ dạng giấy vì tất cả thông tin đã được quản lý trên cơ sở dữ liệu địa chính và chỉ xuất sổ giấy khi có nhu cầu. Điều này cho thấy rõ hiệu quả của cơ sở dữ liệu địa chính trong lập và quản lý hồ sơ địa chính.
Ngoài ra, quận cũng đang quản lý và lưu trũ̃ 69.671 hồ sơ thủ tục đăng ký đất đai qua các thời kỳ, đã được số hóa và gắn kết trực tiếp với cơ sở dữ liệu địa chính. Tuy nhiên, do hạn chế về kinh phí và nhân lực nên quận chỉ thực hiện số hóa một số thành phần hồ sơ cần thiết theo quy định của DONRE (2016).

Tóm lại, cơ sở dữ liệu hồ sơ thủ tục đăng ký đất đai của quận dù không chứa đầy đủ tất cả các thành phần như hồ sơ gốc ở dạng giấy và chưa được quản lý theo đúng quy định hiện hành nhưng đã cơ bản đảm bảo hiệu quả cho công tác quản lý hồ sơ địa chính cũng như quá trình thực hiện các thủ tục đăng ký đất đai tại địa phương.

- Đối với việc quy trình hóa thủ tục hành chính về đất đai theo chuẩn ISO:

Quận 6 đã quy trình hóa các thủ tục hành chính về đất đai theo chuẩn ISO, đúng theo bộ thủ tục hồ sơ hành chính về đất đai của Ủy ban nhân dân TP.HCM. Thống kê hồ sơ tác nghiệp theo quy trình xử lý hồ sơ đất đai được trình bày ở Bảng 2 (BOLRD6, 2017).

Bảng 2. Thống kê hồ sơ tác nghiệp theo quy trình xử lý hồ sơ đất đai

\begin{tabular}{|c|c|c|}
\hline \multicolumn{2}{|c|}{ STT Tên quy trình } & \multirow{2}{*}{$\begin{array}{c}\text { Số lượng } \\
\text { (hồ sơ) }\end{array}$} \\
\hline 1 & $\begin{array}{l}\text { Chuyển mục đích sử dụng } \\
\text { đất }\end{array}$ & \\
\hline 2 & Biến động in trang 3-4 & 7.529 \\
\hline 3 & Cấp mới Giấy chứng nhận & 6.240 \\
\hline 4 & $\begin{array}{l}\text { Cấp mới giấy chứng nhận (bồ } \\
\text { sung tài sản/ giây hợp thức } \\
\text { hóa) }\end{array}$ & 3.229 \\
\hline 5 & Chỉnh lý - Điều chỉnh & 1.865 \\
\hline 6 & Chuyển quyền & 12.180 \\
\hline 7 & Cứu xét & 575 \\
\hline 8 & Đăng ký biến động - Cấp đổi & 6.511 \\
\hline 9 & $\begin{array}{l}\text { Đăng ký biến động - Cấp đổi } \\
\text { (in trang 3-4) }\end{array}$ & 405 \\
\hline 10 & Giao dịch bảo đảm & 29.979 \\
\hline 11 & Tăng giảm diện tích & 728 \\
\hline 12 & Thu hồi & 582 \\
\hline 13 & Xác nhận nghĩa vụ tài chính & 255 \\
\hline & Tổng cộng & 70.098 \\
\hline
\end{tabular}

- Đối với quá trình quản lý và điều hành công việc của lãnh đạo:

Cơ sở dữ liệu địa chính và phần mềm HCM's Land MDP đã trợ giúp các cấp lãnh đạo thực hiện công tác chỉ đạo, điều hành công việc trên môi 
trường quản lý điện tử như: tổ chức, điều hành, theo dõi và tổng hợp tình hình xử lý công việc theo Hình 2 (DONRE, 2016). Kết quả này giúp lãnh đạo có thể quản lý chặt chẽ được công việc, con người, hồ sơ, làm cơ sở để đôn đốc, nhắc nhở, đẩy nhanh tiến độ và minh bạch hóa quá trình xử lý hồ sơ đất đai của địa phương.

- Đối với quá trình tra cứu và truy xuất thông tin đất đai:

Cơ sở dữ liệu địa chính hỗ trợ khả năng tra cứu và truy xuất thông tin thửa đất theo nhiều tiêu chí bằng phần mềm HCM's Land MDP, cụ thể:

Tra cứu thông tin đất đai đa tiêu chí.

Tra cứu thông tin thuộc tính bằng việc xác định vị trí thửa đất trên bản đồ.

Tra cứu tổng hợp thông tin thửa đất bằng bảng thông tin hồ sơ đất đai.

Truy xuất các thông tin đất đai thường xuyên, như: Tổng hợp, báo cáo tình hình cấp giấy chứng nhận; Xuất danh sách công khai cấp giấy chứng nhận; Thống kê kiểm kê đất đai; Xuất danh sách chủ theo đơn vị hành chính; Quản lý đợt đăng ký đất đai; Tạo và in sổ bộ địa chính các loại; Tạo hồ sơ địa chính điện tử; Tạo danh mục các loại; Quản lý hồ sơ gốc; Quản lý biến động đất đai; Cập nhật và thông báo tự động thông tin ngăn chặn,...

Nhìn chung, cơ sở dữ liệu địa chính của Quận 6 được khai thác khá hiệu quả, giúp tinh giảm các công việc trùng lắp, xử lý khối lượng hồ sơ lớn, tiết kiệm được thời gian và giảm thiểu tối đa nguồn nhân lực.

\subsection{3. Đánh giá thực trạng chia sẻ cơ sở dữ liệu địa chính}

Theo BOLRD6 (2017), Quận 6 là đơn vị đầu tiên được trang bị hệ thống hỗ trợ chia sẻ thông tin đất đai từ cơ sở dữ liệu địa chính bao gồm:

- Kết nối với cổng thông tin đất đai và tin nhắn SMS:

Tiện ích này giúp theo dõi tiến độ xử lý hồ sơ qua cổng thông tin đất đai và tin nhắn SMS, mang lại nhiều thuận tiện cho người dân và các cấp lãnh đạo khi có nhu cầu tiếp cận với thông tin đất đai thể hiện ở Hình 3 \& 4 (DONRE, 2014).

- Liên thông với cấp phường:

Quận 6 đã triển khai thành công mô hình cấp giâyy chứng nhận liên thông phường - quận nhờ kết nối cơ sở dữ liệu địa chính với Ửy ban nhân dân 14 phường thông qua đường truyền chuyên dụng, tạo điều kiện thuận lợi cho người dân khi thực hiện thủ tục đề nghị cấp giấy chứng nhận cũng như giảm áp lực cho Bộ phận tiếp nhận hồ sơ của BOLRD6 (2017) (Hình 5).

Tuy nhiên, đến cuối năm 2016, do số lượng hồ sơ đề nghị cấp giấy chứng nhận lần đầu không còn nhiều, không còn gây áp lực tiếp nhận hồ sơ đối với Chi nhánh Văn phòng Đăng ký đất đai nên hiện nay mô hình này đã tạm thời ngưng hoạt động.

- Liên thông thuế điện tử:

Đây là mô hình liên thông điện tử giữa cơ quan thuế với cơ quan Tài Nguyên và Môi Trường (Hình 6)(DONRE, 2016). Với mô hình này, người nộp thuế chỉ cần nộp hồ sơ và nhận kết quả tại Văn phòng Ủy ban nhân dân quận trong khoảng 5 ngày làm việc và không phải đến cơ quan thuế để thực hiện các thủ tục thu nộp.

Tuy nhiên, sau một thời gian ngắn triển khai thử nghiệm (vào quý 1 năm 2016) với 681 hồ sơ thì mô hình này cũng bị ngưng hoạt động vì chưa có sự thống nhất quan điểm về thành phần hồ sơ và phương thức liên thông điện tử giữa cơ quan Tài nguyên và Môi trường với cơ quan thuế.

- Kết nối với cổng thông tin một cửa điện tử TP.HCM:

Từ đầu năm 2016 đến nay, Quận 6 đã triển khai Phần mềm Một cửa điện tử quản lý đất đai tại Bộ phận một cửa của Văn phòng Ủy ban nhân dân Quận để thực hiện tiếp nhận, luân chuyển hồ sơ đất đai theo quy trình thống nhất, liên thông 3 cấp, nhằm quản lý hồ sơ đất đai theo mô hình tập trung trên toàn thành phố. Đồng thời, phần mềm này đã được liên thông với hệ thống Một cửa điện tử của TP.HCM, cho phép tra cứu thông tin về tình trạng xử lý hồ sơ đất đai mọi lúc, mọi nơi thông qua mạng internet và tin nhắn điện thoại, giúp công khai, minh bạch thời gian và tiến độ giải quyết hồ sơ đất đai (Hình 7).

Nhìn chung, việc chia sẻ thông tin đất đai từ cơ sở dữ liệu địa chính của Quận 6 được thực hiện chưa thành công do tồn tại nhiều bất cập từ nhiều phía. Hiện nay, lãnh đạo địa phương và các cơ quan có liên quan đang cố gắng khắc phục nhằm tăng cường hiệu quả chia sẻ cơ sở dữ liệu địa chính của Quận.

\subsection{4. Đánh giá chung}

- Uu điểm: 


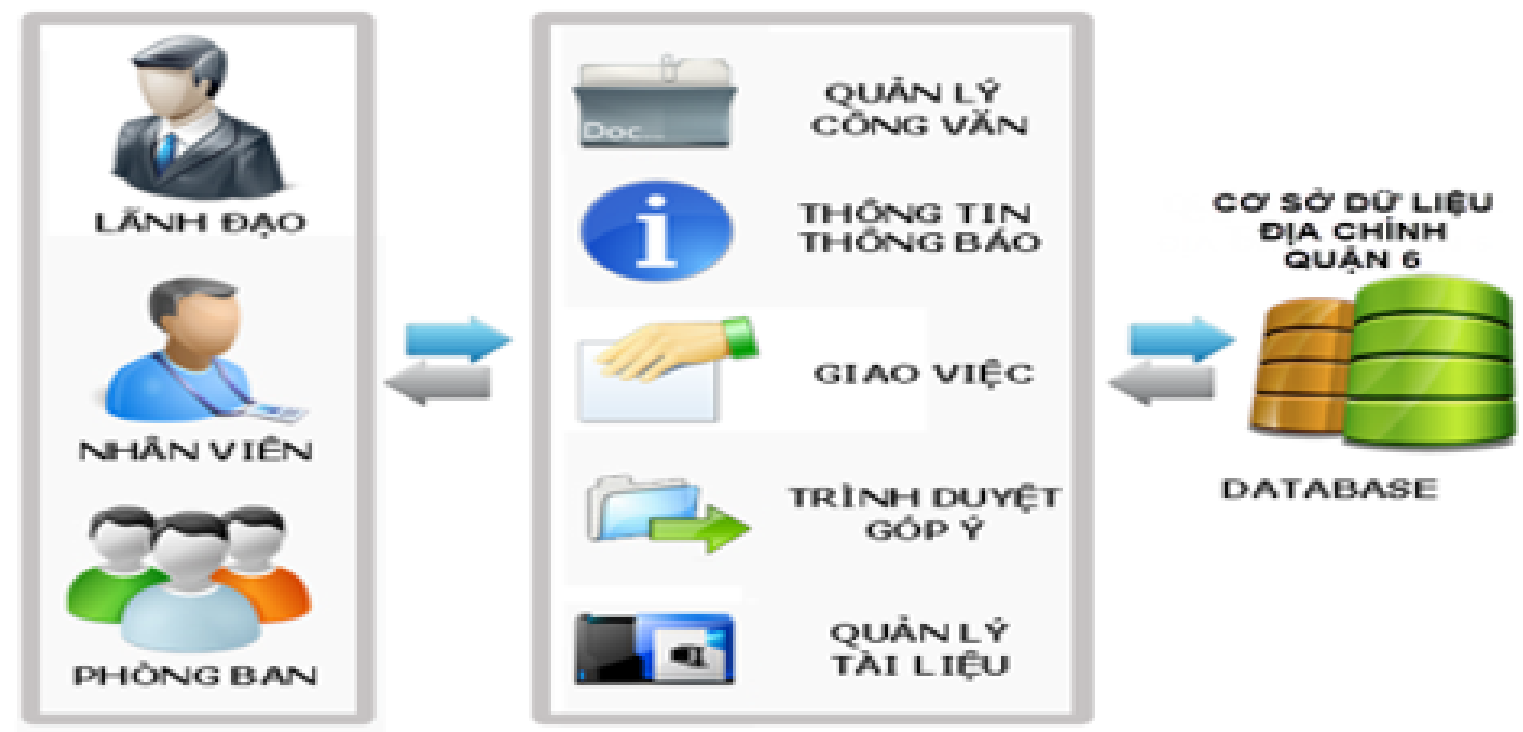

Hình 2. Môi trường quản lý điện tử.

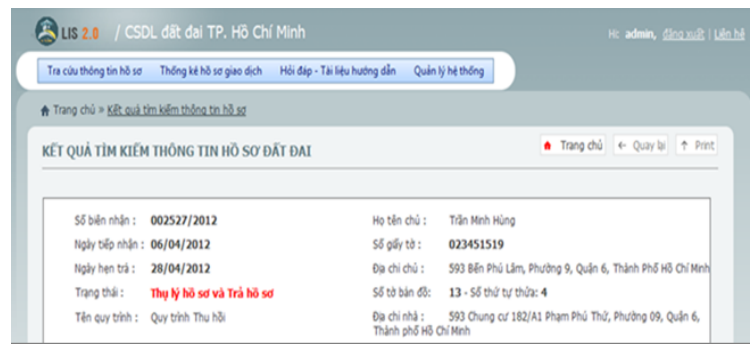

Hình 3. Giao diện theo dõi tiến độ xử lý hồ sơ qua web.

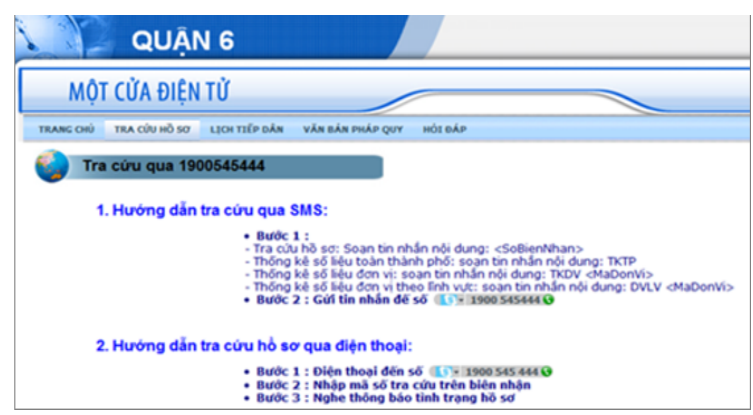

Hình 4. Giao diện theo dõi tiến độ xử lý hồ sơ qua tin nhắn SMS.

Cơ sở dữ liệu địa chính được vận hành thường xuyên và khai thác hiệu quả.

Hỗ trợ chuẩn hóa các quy trình xử lý hồ sơ đất đai và báo cáo tổng hợp nhanh chóng, kịp thời.

Phần mềm HCM's Land MDP hỗ trợ tốt công tác xây dựng và vận hành cơ sở dữ liệu.

Hình thành đội ngũ công chức chuyên nghiệp, có năng lực, đáp ứng yêu cầu tin học hóa, hiện đại hóa ngành quản lý đất đai.

Nâng cao hiệu quả cải cách hành chính, tăng khả năng tiếp cận thông tin đất đai của người dân.

Giúp công tác quản lý đất đai tại Quận 6 dần hình thành được môi trường làm việc điện tử.

- Hạn chế:

Nội dung và cấu trúc cơ sở dữ liệu được xây dựng theo quy định cũ tại thông tư 17/2010/TTBNTMT, chưa đáp ứng các yêu cầu theo quy định mới của ngành tại thông tư 75/2015/TTBTNMT.

Chưa vận hành cơ sở dữ liệu địa chính theo mô hình tập trung.

Hệ thống máy chủ và đường truyền kết nối chưa đáp ứng yêu cầu.

Chưa cập nhật biến động không gian địa chính vào cơ sở dữ liệu và khai thác thông tin không gian trong công tác cấp giấy chứng nhận chưa hiệu quả.

Chưa phối hợp liên ngành về kết nối thông tin giữa các cơ quan, đơn vị. Khả năng tiếp cận thông tin đất đai của người dân và doanh nghiệp còn nhiều hạn chế.

Chưa triển khai các dịch vụ công trực tuyến trong lĩnh vực quản lý đất đai. 


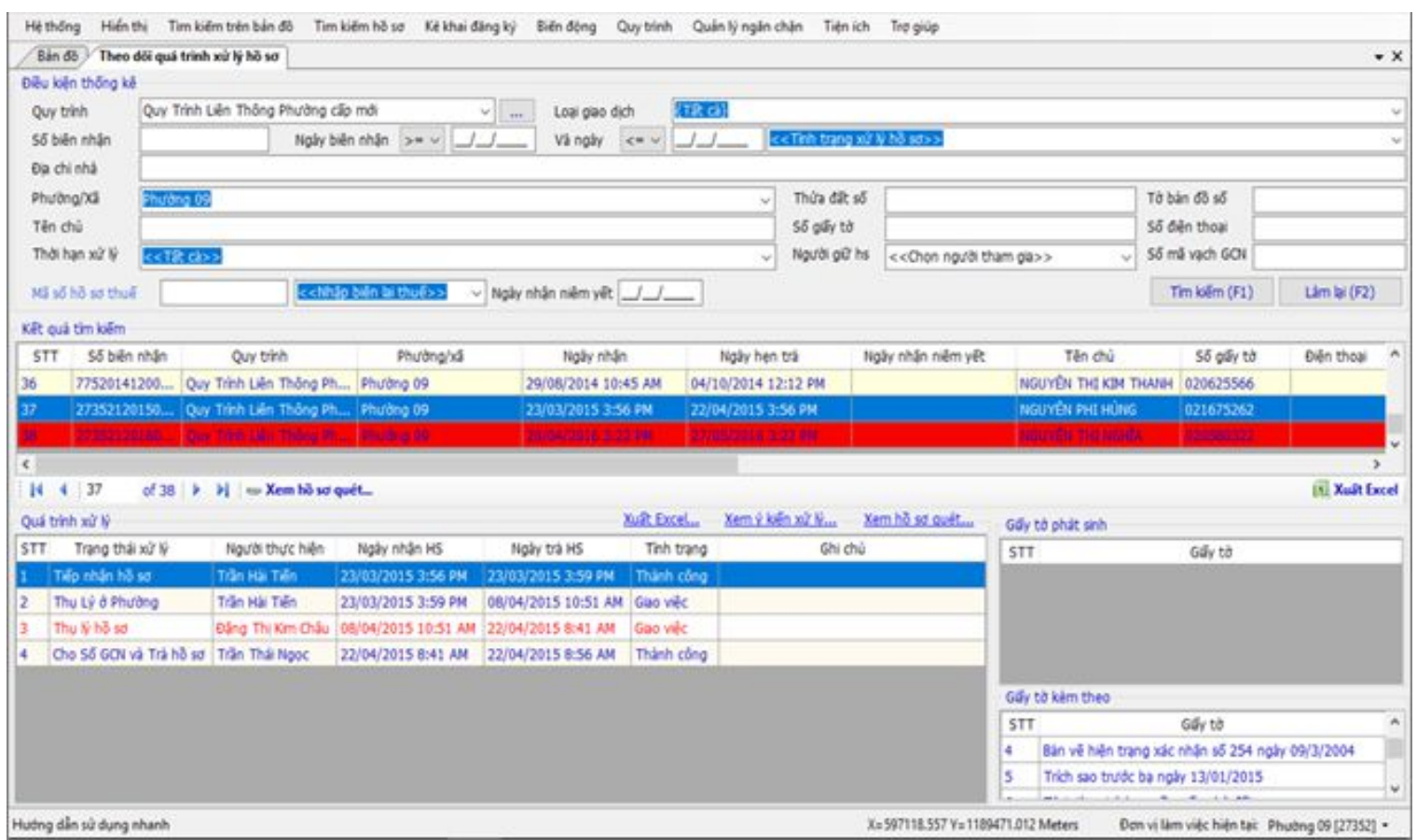

Hình 5. Kết quả cấp giấy chứng nhận liên thông phường - quận.

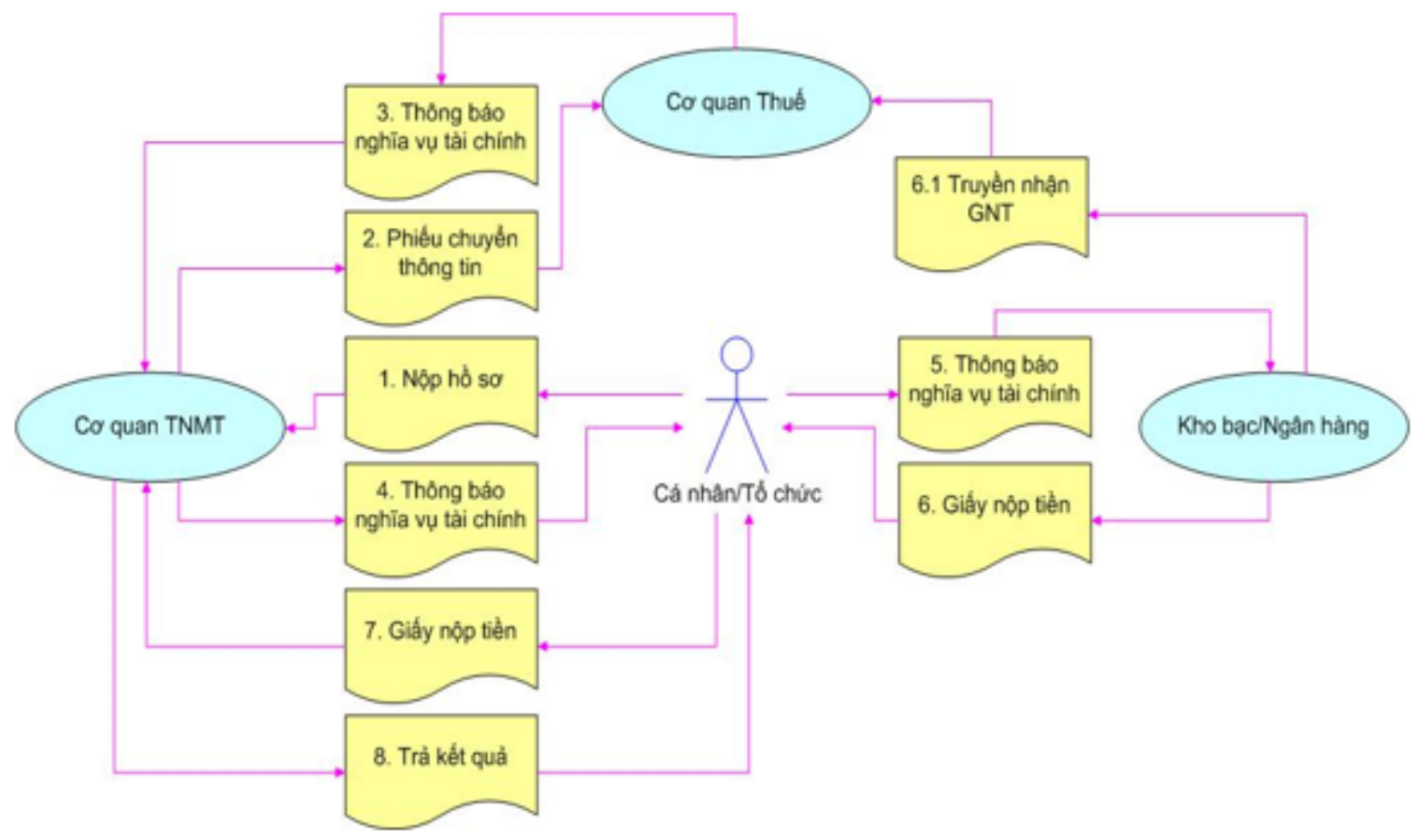

Hình 6. Quy trình Liên thông thuế điện tử.

Công tác đào tạo và xây dựng đội ngũ chuyên viên quản trị hệ thống còn hạn chế.
- Nguyên nhân:

Nhận thức về tầm quan trọng của cơ sở dữ liệu 


\section{Tra cứu hồ sơ}

\begin{tabular}{|c|c|c|c|c|c|c|c|}
\hline & \multicolumn{7}{|l|}{ Xác nhận thông tin } \\
\hline & Mă số biên nhận (") & 27382. & 120.18 .001278 & \multirow{2}{*}{\multicolumn{4}{|c|}{$\begin{array}{l}\text { Bạn hãy nhập chính xác số biên nhân trên phiếu } \\
\text { biên nhận và băm nút "Tra cứu" đế xem thồng } \\
\text { tin hồ sơ của bạn. }\end{array}$}} \\
\hline \multicolumn{4}{|c|}{ 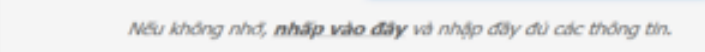 } & & & & \\
\hline sit & \multicolumn{2}{|l|}{ Thú tục } & Số biên nhận & Họ và tên & Ngày nộp & $\begin{array}{l}\text { Ngày hẹn } \\
\text { trà }\end{array}$ & Tinh trạng \\
\hline 1 & \multicolumn{2}{|c|}{$\begin{array}{l}\text { Thẽ chã̃ (Ap dụng cho dôi tuợng là cá } \\
\text { nhẩn) }\end{array}$} & 27382.120 .18 .001278 & LUUU HUę OHI & $05 / 07 / 2018$ & $06 / 07 / 2018$ & \\
\hline
\end{tabular}

Hình 7. Giao diện tra cứu hồ sơ trên cổng thông tin một cửa điện tử.

địa chính chưa đủ rõ.

Tư duy quản lý, xử lý công việc bằng giấy còn ảnh hưởng nặng nề.

Vai trò, chức năng, phương thức hoạt động của đơn vị chậm đổi mới.

Việc quán triệt, tổ chức thực hiện các quy định, hướng dẫn về quản lý, cập nhật cơ sở dữ liệu đơn vị, nhất là người đứng đầu thiếu quyết liệt, hiệu quả thấp và chưa kinh nghiệm.

Cơ sở vật chất, hạ tầng công nghệ thông tin phục vụ việc lưu trữ, quản lý, vận hành, cập nhật cơ sở dữ liệu còn thiếu, chất lượng đường truyền và cấu hình nhiều thiết bị chưa đáp ứng yêu cầu.

Việc tích hợp, đồng bộ cơ sở dữ liệu giữa các cấp thực hiện chưa tốt. Mô hình vận hành và cấu trúc cơ sở dữ liệu chưa phù hợp với định hướng chung của ngành.

Phần mềm quản lý, cập nhật cơ sở dữ liệu hiện hữu chưa đáp ứng yêu cầu theo quy định mới.

\subsection{Một số giải pháp hoàn thiện công tác quản lý, khai thác và chia sẻ cơ sở dữ liệu địa chính Quận 6}

Dựa vào thực trạng tại địa phương, nhu cầu thực tế và quy định hiện hành của ngành về quản lý, khai thác và chia sẻ cơ sở dữ liệu địa chính, đề tài xin đề xuất một số giải pháp hoàn thiện công tác quản lý, khai thác và chia sẻ cơ sở dữ liệu địa chính Quận 6 theo thứ tự ưu tiên như sau:

Thứ nhất, vạch ra các giải pháp về quản lý và chính sách nhằm nâng cao nhận thức của người dùng về tầm quan trọng của cơ sở dữ liệu địa chính và đảm bảo tính toàn vẹn của cơ sở dữ liệu, cư thể: Giảm dần tư duy quản lý, xử lý công việc bằng giấy; thực hiện nghiêm túc các quy định về quản lý, cập nhật cơ sở dữ liệu ở đơn vị; có cơ chế giám sát việc tích hợp và dồng bộ cơ sở dữ liệu giữa các cấp.

Thứ hai, tăng cường đầu tư cơ sở vật chất và hạ tầng công nghệ thông tin, bao gồm: Đầu tư, nâng cấp hệ thống máy chủ và hệ thống lưu trữ cơ sở dữ liệu của địa phương nhằm đáp ứng nhu cầu vận hành và khả năng tăng trưởng trong tương lai của dữ liệu địa chính; mở rộng băng thông của hệ thống mạng MetroNET lên tối thiểu 16 Mbps nhằm đảm bảo kết nối thông suốt giữa các cơ quan, đơn vị.

Thứ ba, hoàn thiện mô hình quản lý, khai thác và chia sẻ cơ sở dữ liệu địa chính theo mô hình tập trung cấp tỉnh để thuận lợi cho việc khai thác, vận hành, bảo trì và bảo mật cơ sở dữ liệu; đảm bảo cơ sở dữ liệu luôn được duy trì, cập nhật thường xuyên và đồng bộ kịp thời giữa các cấp, 
bao gồm: (1) Mô hình cơ sở dữ liệu địa chính tập trung toàn thành phố nhằm quản lý tập trung dữ liệu tại một mối, đặc biệt là quản lý và đồng bộ biến động đất đai các cấp theo thời gian thực; (2) Mô hình bản đồ địa chính tập trung giúp cán bộ được phân công có thể cập nhật, chỉnh lý biến động không gian trực tiếp trên một nền bản đồ duy nhất, đảm bảo tính thống nhất, kịp thời của các biến động đất đai và tránh tình trạng trùng thửa,...; và (3) Xây dựng kho hồ sơ thủ tục đăng ký đất đai dạng số tập trung và đồng bộ với cơ sở dữ liệu địa chính của thành phố nhằm củng cố tính pháp lý của cơ sở dữ liệu, đáp ứng yêu cầu bảo quản vĩnh viễn hồ sơ pháp lý gốc và rút ngắn thời gian giải quyết các dạng hồ sơ hành chính về đất đai.

Thứ tư, xây dựng Phần mềm hệ thống thông tin đất đai TP.HCM (Phần mềm LIS): Thực tế cho thấy, phần mềm HCM's Land MDP là công cụ hỗ trợ rất hiệu quả cho công tác quản lý, khai thác và chia sẻ cơ sở dữ liệu địa chính. Tuy nhiên, trước nhiều thay đổi trong công tác quản lý đất đai và cơ sở dữ liệu đất đai hướng đến nền quản lý đất đai điện tử, hiện đại của MONRE (2015) thì kiến trúc và chức năng của phần mềm hiện hữu không đủ đáp ứng yêu cầu. Do đó, cần thiết phải xây dựng một Phần mềm hệ thống thông tin đất đai mới cho TP.HCM (gọi chung là phần mềm LIS) sao cho vừa hiện đại, vừa phù hợp quy định hiện hành cũng như đáp ứng được các yêu cầu đặc thù của thành phố nhằm hỗ trợ quản lý, khai thác và chia sẻ cơ sở dữ liệu đất đai hiệu quả hơn.

Thứ năm, vận hành quy trình bổ sung, cập nhật và hoàn thiện cơ sở dữ liệu địa chính: Kết quả đánh giá thực trạng cho thấy cơ sở dữ liệu địa chính Quận 6 còn tồn tại nhiều hạn chế. Vì vậy, rất cần thiết phải thực hiện rà soát, bổ sung, cập nhật và hoàn thiện cơ sở dữ liệu địa chính của Quận theo đúng quy định của MONRE (2015). Tuy nhiên, do biến động đất đai của địa phương xảy ra rất thường xuyên và liên tục nên cần phải triển khai song song 2 tiến trình (Hình 8 ):

- Tiến trình 1: là quá trình cập nhật, chỉnh lý tất cả các biến động đất đai xảy ra hằng ngày trên địa bàn vào cơ sở dữ liệu địa chính (gọi là cơ sở dữ liệu vận hành). Tiến trình này được thực hiện bởi cán bộ của hệ thống Văn phòng Đăng ký đất đai (ở thành phố và quận) bằng phần mềm LIS, nhằm đảm bảo toàn bộ biến động mới phát sinh đều được ghi nhận vào cơ sở dữ liệu.

- Tiến trình 2: là quá trình rà soát, bổ sung,

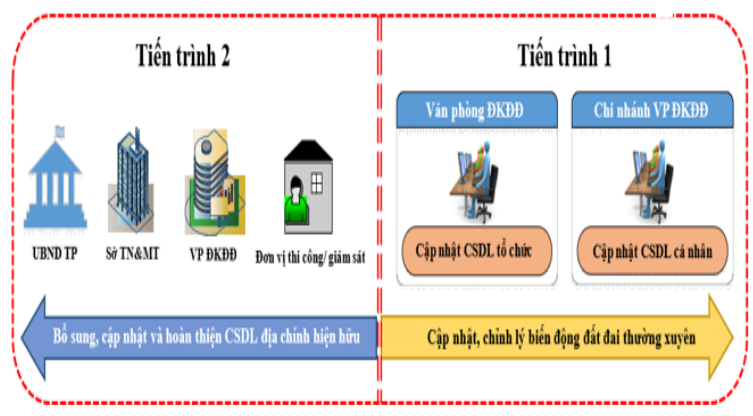

Hình 8. Mô hình bổ sung, cập nhật và hoàn thiện cơ sở dữ liệu địa chính.

cập nhật và chuyển đổi cơ sở dữ liệu địa chính của Quận sang cấu trúc dữ liệu mới theo thông tư 75/2015/TT-BTNMT (gọi là cơ sở dữ liệu thi công). Tiến trình này được thực hiện bởi đơn vị tư vấn dự án của Sở Tài nguyên và Môi trường, gồm 6 bước đúng theo hướng dẫn của Bộ Tài nguyên và Môi trường tại tiểu mục 2 , thông tư 05/2017/TT-BTNMT.

- Sau cùng, đồng bộ - tích hợp 2 cơ sở dữ liệu (vận hành và thi công) của 2 tiến trình trên để có được cơ sở dữ liệu địa chính hoàn chỉnh sẵn sàng cho quá trình đồng bộ và tích hợp cơ sở dữ liệu các cấp.

Thứ sáu, xây dựng và kiện toàn Hệ thống thông tin đất đai TP.HCM : Theo DITD (2016), một hệ thống thông tin đất đai hoàn thiện, hoạt động có hiệu lực, hiệu quả sẽ trở thành công cụ hỗ trợ tích cực cho quá trình quản lý, khai thác và chia sẻ cơ sở dữ liệu địa chính. Do đó, cần phải xây dựng một hệ thống thông tin đất đai hoàn chỉnh cho toàn thành phố với kiến trúc và mô hình hệ thống thông tin phù hợp với kiến trúc của chính quyền điện tử và mô hình thành phố thông minh đang được triển khai tại TP.HCM.

\section{Kết Luận}

Nghiên cứu đã đánh giá được thực trạng quản lý, khai thác và chia sẻ cơ sở dữ liệu địa chính tại Quận 6, TP.HCM. Với sự hỗ trợ của phần mềm HCM's Land MDP, quá trình quản lý và khai thác cơ sở dữ liệu địa chính của địa phương được thực hiện khá tốt, phục vụ rất đắc lực cho hầu hết các lĩnh vực của công tác quản lý đất đai trên địa bàn; đồng thời giúp ngành quản lý đất đai của Quận 6 dần hình thành được môi trường làm việc điện tử. Tuy nhiên, do là một trong những đơn vị đầu tiên xây dựng và vận hành cơ sở dữ liệu địa chính nên cơ sở dữ liệu của Quận 6 vẫn còn 
tồn tại nhiều hạn chế; đặc biệt là hạn chế về cấu trúc dữ liệu, mô hình vận hành và quá trình chia sẻ cơ sở dữ liệu địa chính với các đối tượng có liên quan. Trên cơ sở đó, nghiên cứu đề xuất một số giải pháp nhằm hoàn thiện công tác quản lý, khai thác và chia sẻ cơ sở dữ liệu địa chính của địa phương, làm tiền đề để Quận 6 hoàn thiện cơ sở dữ liệu địa chính và đồng bộ, tích hợp cơ sở dữ liệu giữa các cấp, tiến đến xây dựng thành công mô hình cơ sở dữ liệu địa chính tập trung trên toàn địa bàn TP.HCM.

\section{Lời Cảm Ơn}

Kết quả này thuộc một phần đề tài khoa học và công nghệ cấp cơ sở "Nghiên cứu đề xuất giải pháp hoàn thiện mô hình quản lý, khai thác sử dụng và chia sẻ cơ sở dữ liệu địa chính tại Quận 6, TP.HCM", mã số: CS-CB17-QLĐĐ\&BĐS-02 do Trường Đại học Nông Lâm TP.HCM làm chủ quản.

\section{Tài Liệu Tham Khảo (References)}

BOLRD6 (Branch Office for Land Registration of District 6). (2017). A report on cadastral database operation. Ho Chi Minh City, Vietnam.
DITD (Department of Information Technology and Natural Resources Data). (2016). A draft on general architecture of land information system in Vietnam. Ha Noi, Vietnam: DITD Office.

DONRE (Department of Natural Resources and Environment). (2014). General report of building land database in Ho Chi Minh City. Ho Chi Minh City, Vietnam: DONRE Office.

DONRE (Department of Natural Resources and Environment). (2016). Decision No. 3544/QD-STNMTBDVT on temporary regulation of management, utilization and updating land databases. Ho Chi Minh City, Vietnam: DONRE Office.

MONRE (Ministry of Natural Resources and Environment). (2015). The implementation guidelines of project for improved land governance and databases in Vietnam (VILG). Hanoi, Vietnam: MONRE Office.

MONRE (Ministry of Natural Resources and Environment). (2015). Circular of 75/2015/TT-BTNMT dated 28/12/2015 on technical regulation about land databases. Ha Noi, Vietnam: MONRE Office.

Truong, L. D. T. (2012). Building land management database in District 6, Ho Chi Minh City (Unpublished master's thesis). Nong Lam University, Ho Chi Minh City, Vietnam. 